Original Article

\title{
PREVALENCE OF ORAL MUCOSAL LESIONS AND THEIR CO - RELATION TO HABITS IN PATIENTS VISITING A DENTAL SCHOOL OF SOUTH KARNATAKA : A CROSS SECTIONAL SURVEY- 2012
}

\author{
Mithra N. Hegde', Radhika Jain ${ }^{2} \&$ Ashwitha Punja ${ }^{3}$ \\ ${ }^{1}$ Professor \& HOD, ${ }^{2}$ Post Graduate, ${ }^{3}$ Professor, Department of Conservative Dentistry \& Endodontics, A.B. Shetty \\ M emorial Institute of Dental Sciences, Nitte University, Mangalore - 575 018, India. \\ Correspondence : \\ Radhika Jain \\ Post Graduate, Department of Conservative Dentistry \& Endodontics, A.B. Shetty Memorial Institute of Dental Sciences \\ Nitte University, Mangalore - 575 018, India \\ M obile : +918884407451 E-mail : radhikajn14@gmail.com
}

\begin{abstract}
:
The aim of the present study was to determine the prevalence of oral mucosal lesions and their co-relation to deleterious habits of smoking, tobacco and alcohol consumption. 2000 patients visiting both rural and urban centres were screened for oral lesions and information regarding habits was obtained through a questionnaire. The results showed the prevalence of oral mucosal lesion to be $16.7 \%$ in the study population. The most frequent observation was the presence of Fordyce's spots(6.2\%) followed by smoker's palate( $5.6 \%)$, leukoedema(3.15\%), leuko plakia(2.1\%), oral sumucous fibrosis(2\%), recurrent aphthous ulcers and lingual varices(1.6\%), Lichen planus(1.2\%) and oral candidiasis(1\%). The habits were found to be associated with increased prevalence of oral mucosal lesions, especially in men. The study concluded the need for formulation of public health programmes discouraging these practises and public awareness of their ill-effects.
\end{abstract}

Keywords: oral mucosal lesions, prevalence, habits

\section{Introduction:}

Oral malignancies collectively form the sixth most common type of cancer in the world. ${ }^{1}$ The Indian subcontinent has long been regarded as the epicentre of oral cancer around the globe and is recognised as a major health problem. It imposes a huge a burden in terms of diagnosis, survival and the use of already stretched out health care facilities in the course of treatment. ${ }^{2,3}$

Epidemiological studies help in determining the incidence, prevalence and the severity of diseases. They also help in assessing the distribution, the risk factors and associated aetiology. This information is useful in the formulation of health care programmes Access this article online Quick Response Code

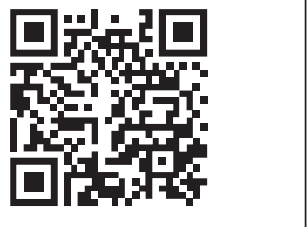
at the primary level to spread awareness, help guide in early diagnosis and lead to prompt treatment.

Dental professionals, in recent times, have become increasingly aware of the significance of oral mucosal lesions and the documented inclination of 'potentially malignant lesions' to lead to cancer. Tobacco and alcohol have long been recognised as risk factors in the development of oral malignancies. ${ }^{4,5,6}$ Thus this paper aims to evaluate the prevalence of oral mucosal lesions in South Karnataka district and to correlate the findings with habits of consuming tobacco and alco hol in the population.

\section{Materials And Methods:}

Two thousand patients were examined under the study. These patients included those who came seeking treatment for dental problems at the outpatient department of A. B. Shetty Memorial Institute of Dental Sciences and at the rural centres instituted by Nitte University at Bailoor, Mundkur and Nitte from $1^{\text {st }}$ June to $31^{\text {st }}$ August 2012. These patients were divided into four groups- less than 20 years of age, 20-40, 41-60 and more than 60 years. Clinical examination of the patients was done by two trained dental surgeons using artificial light, mouth mirror and gauze. Kappa test done to assess 
interexaminer reliability was $80-85 \%$ resulting in high agreement amongst the two examiners. Diagnosis was made on the basis of history, clinical examination and standard accepted guidelines. ${ }^{7}$ Information regarding habits of smoking, tobacco and alcohol consumption was gathered through questionnaire based interviews.

Excluded from the study were those patients who had limited mouth opening, those patients who had recent maxillofacial trauma, those who had intermaxillary fixation and unconscious patients.

The data was analysed using Statistical Package for Social Sciences (SPSS-16 version). Chi- square test was used to determine the association between different variables.

\section{Results:}

Profile of the study population:

Out of the two thousand patients, 960 belonged to the rural strata while 1040 patients were from the urban population. Males formed $55.6 \%$ of the study population and $44.4 \%$ were females. $9.40 \%$ of the participants were under 20 years of age group. Majority of the subjects belonged to the $20-40$ age group, being $63 \%$. The $41-60$ age group included $25 \%$ of the subjects and the least percentage of study population was in the more than 60 years age group, which was $2.70 \%$. M ales outnumbered females in all the age groups under the study.

\begin{tabular}{|c|c|c|}
\hline Age group (years) & Males $(\mathrm{n} \%)$ & Females $(\mathrm{n} \%)$ \\
\hline$<20$ & 102 & 86 \\
\hline $20-40$ & 712 & 546 \\
\hline $41-60$ & 248 & 252 \\
\hline$>60$ & 50 & 4 \\
\hline
\end{tabular}

Prevalence of habits:

The prevalence of habits such as smoking, tobacco chewing and consumption of alcohol was $16 \%, 10 \%$ and $4.5 \%$ respectively. The habit of smoking was most prevalent in the 20 -40 age group (16.85\%) with a higher prevalence in men $(28.23 \%)$ than women $(0.78 \%)$. Majority of the participants smoked cigarettes (77.57\%) and 235 of the total 321 people who smoked belonged to the urban population (73.2\%). The habit of alcohol consumption was seen more in men (7.64\%) as compared to women (0.56\%) and found highest in the 20 -40 age group (5.4\%).

Males (16\%) had a higher tendency to chew tobacco against women (3.15\%) and this habit was observed most in the older age group of 41-60 (18.6\%). The study found that the participants were more likely to consume paan masala or gutkha than other forms such as betel nut betel quid, etc. This habit of chewing tobacco was the most prevalent one in females as compared to smoking and drinking alcohol. In males, the habit of smoking was the most prevalent than tobacco or alcohol consumption.

Prevalence of habits according to age and gender:

\begin{tabular}{|l|c|c|c|c|c|c|}
\hline Age group & \multicolumn{2}{|c|}{ smoking } & \multicolumn{3}{c|}{ Chewing tobacco } & \multicolumn{2}{c|}{ Alcohol drinking } \\
\hline & males & females & males & females & males & Females \\
\hline$<20$ & 26 & 0 & 11 & 0 & 0 & 0 \\
\hline $20-40$ & 205 & 7 & 37 & 0 & 18 & 0 \\
\hline $41-60$ & 32 & 0 & 71 & 22 & 63 & 5 \\
\hline$>60$ & 44 & 0 & 59 & 6 & 4 & 0 \\
\hline
\end{tabular}

Prevalence of lesions:

The oral soft tissue lesions were found to have a prevalence of $16.7 \%$ in the study population. They formed 334 subjects of the study population. Normal mucosal variants were seen in 256 people in the study. The most common mucosal lesion observed was smoker's palate. It was diagnosed in 112 cases, all of which were seen in men.

The prevalence of leukoplakia was $2.1 \%$ in our population. It was found to be most commonly present in the 20-40 year age group. M ales showed a higher prevalence (3.41\%) as compared to females ( $0.45 \%)$. Oral submucous fibrosis was seen in $2 \%$ of the population with highest prevalence observed in 41-60 age group. It was more frequently found in men $(2.96 \%)$ than women $(0.78 \%)$.

Lichen planus was found to be $1.2 \%$ in our study. Females (2.25\%) had a higher predilection for this disease than males $(0.35 \%)$. This disease was mostly seen in the $20-40$ age group. The prevalence of candidiasis was observed to be $1 \%$ in our study population. It was seen more in men (1.3\%) than women $(0.56 \%)$ and most frequently in the 41 60 age group. Recurrent aphthae were present in $1.6 \%$ of the population. Mostlyseen in the 20 -40 age group, it had a higher preponderance in males $(1.97 \%)$ than females (1.7\%). 
A total of 256 normal mucosal variants were recorded in 2000 patients. Fordyce's spots in 71 males (6.38\%) and 53 females (5.96\%). Lingual varices were seen in $26(2.33 \%)$ males with the highest incidence in the 60-69 years age group and in 6 females (0.67\%) with highest incidence in the group aged 60-64 years. Leukoedema was reported in 54 male (4.85\%) patients with peak incidence in those aged 40-44 years, and 9 female (1.01\%) patients with the most in those who are 35-39 and 60-64 years.

Prevalence of lesions:

\begin{tabular}{|l|c|c|}
\hline M ucosal findings & Males $(\mathrm{n} \%)$ & Females $(\mathrm{n} \%)$ \\
\hline Leukoplakia & $38(3.41)$ & $4(0.45)$ \\
\hline Oral submucous fibrosis & $33(2.96)$ & $7(0.78)$ \\
\hline Lichen planus & $20(2.25)$ & $4(0.35)$ \\
\hline Oral candidiasis & $15(1.3)$ & $5(0.56)$ \\
\hline Recurrent aphthous ulcers & $22(1.97)$ & $10(1.1)$ \\
\hline Fordyce's spots & $71(6.38)$ & $53(5.96)$ \\
\hline Lingual varices & $26(2.33)$ & $6(0.67)$ \\
\hline Luekoedema & $54(4.85)$ & $9(1.01)$ \\
\hline Smoker's palate & $112(5.6 \%)$ & \\
\hline
\end{tabular}

\section{Discussion:}

Cross sectional studies are the tools used to determine the prevalence of diseases in a population and to identify the groups which are at high risk.

The prevalence of leukoplakia was $2.1 \%$ in our study which is more than that reported by Matthew et al in Manipal. ${ }^{8}$ These findings were also consistent with those of Bhatnagar et al(2.38) in Uttar Pradesh, India(2013) and Espinoza in Chile $(2003)^{10}$. However, a very high prevalence was reported by Oakley et al $(13 \%)^{11}$ in the habitual areca nut chewer high-school students of Micronesia and by Zhang et al (9.18\%) in China ${ }^{12}$. As with other studies, our study also shows an association between smoking habits and leukoplakia. The results were statistically significant $\left(\chi^{2}\right.$ $=42.02, p<0.001$ ). Also, oral leukoplakia was found to be more prevalent in men than women. This could be due to the very high number of male smokers as compared to females. Leukoplakia was most commonly found on the buccal mucosa followed by the labial mucosa and the commissural area. It was also seen in the retromolar region and alveolar ridge.
The prevalence of oral submucous fibrosis found to be $2 \%$ in our population was less as compared to that observed by Sharma et al (3.39\%) in the rural areas of Jaipur. ${ }^{13}$ This could be due to the high number of participants in that study consuming areca nut and gutkha. The relation of consuming these substances with the increased prevalence of OSM $\mathrm{F}$ is reinforced by our study (odds ratio= 93.66, $\left.\quad ?^{2}=277.84, p<0.001\right)$. The signs seen were generalised blanching, presence of fibrotic bands in the oral mucosa and the patients' complained of burning sensation. Oral submucous fibrosis was mostly seen in the 41-60 age groups which could be attributed to the habit of chewing paan and gutkha prevailing in this age group.

Lichen planus has an overall prevalence of $1.5 \%$ amongst Indians which was comparable to that found in our study. This was in accordance with the prevalence reported by Axell \& Rundquist. ${ }^{14}$ This study found no significant correlation between tobacco consumption and Lichen planus (odds ratio $=1.7, ?^{2}=1.07$ ) although the prevalence was higher in subjects with habits. The consumption of tobacco has the potential to alter the course of disease and should not be overlooked. The buccal mucosa was the most common site to be afflicted by Lichen planus in our study with reticular type being the most common variant present.

The prevalence of oral Candidiasis in our population is lower in our population as compared to that in South Brazil documented by Carrard V et al(14\%). ${ }^{15}$ Also these lesions were found to be significantly associated with female gender as opposed to that observed in the current study.

The most common type recorded in our study was the psuedomembranous candidasis. The higher prevalence of candidiasis in older age group in our study reaffirms extremes of age as a risk factor for oral candidiasis due to decreased immunity and the use of complete dentures. The habit of smoking was more prevalent in young adults and there was no significant association found between smoking and candidiasis.

The presence of recurrent aphthae being $1.6 \%$ in our 
population is drastically less than found in a study in Jordanian adults where it was concluded to be a common problem. ${ }^{16}$ However, these results were comparable to those of Chattopadhyay found in the American population and García-Pola Vallejo MJ in the Spanish population. ${ }^{17,18}$ The most common site in our observations was the lip followed by the buccal mucosa. The lesions were found more in males who were non-smokers.

The information was gathered from questionnaire surveys which could lead to bias on the subject's part. The limited

\section{References:}

1. Parkin DM, Bray F, Ferlay J, Pisani P: Global cancer statistics, 2002. CA:Cancer J ournal for Clinicians 2005;55(2):74-108.

2. Petersen PE. The World Oral Health Report 2003: continuous improvement of oral health in the 21st century - the approach of the WHO Global Oral Health Programme. Community Dent Oral Epidemiol 2003;31:3-23.

3. Ferlay J, Shin HR, Bray F, Forman D, M athers C, Parkin DM . GLOBOCAN 2008 v2.0, Cancer incidence and mortality worldwide: IARC CancerBase No. 10 [Internet]. Lyon, France: International Agency for Research on Cancer; 2010.

4. Jaber M A, Porter SR, Gilthorpe. Risk factors for oral epithelial dysplasia the role of smoking and alcohol. Oral Oncology 1999;35:151-6.

5. Moreno-Lopez LA, Esparza-Gomez GC, Gonzalez-Navarro A. Risk of oral cancer associated with tobacco smoking, alcohol consumption and oral hygiene: a case- control study in Madrid, Spain. Oral Oncol 2000;36:170-4.

6. Yen AM, Chen SC, Chen TH. Dose-response relationships of oral habit associated with the risk of oral pre-malignant lesions among men who chew betel quid. Oral Oncology 2007;43:634-8.

7. Axell T, Pindborg JJ, Smith CJ, van der Waal I. Oral white lesions with special reference to precancerous and tobacco-related lesions: conclusions of an international symposium held in Uppsala, Sweden, May 18-21 1994. J Oral Pathol M ed 1996;25:49-54.

8. Mathew AL, Pai KM, Sholapurkar AA, Vengal M. Theprevalenceoforal mucosallesionsinpatientsvisitingadentalschoolinSouthernIndia. Indian J Dent Res 2008;19(2):99-103.

9. Bhatnagar P, Rai S, Bhatnagar G, Kaur M , Goel S, Prabhat M . Prevalence study of oral mucosal lesions, mucosal variants, and treatment size of the study sample is another shortcoming along with the fact that detailed data on the predictors of oral lesions such as nutritional status could not be assessed.

\section{Conclusion:}

The study observes the increased risk of oral submucous fibrosis with consumption of tobacco such as gutkha and paan masala. Also, the habit of smoking has been reaffirmed as a risk factor for oral leukoplakia. Interventional public health programmes discouraging the use of to bacco should be formulated.

required for patients reporting to a dental school in North India: In accordance with WHO guidelines. I Family Community Med 2013;20(1):41-8.

10. Espinoza I, Rojas R, Aranda W, Gamonal J. Prevalence of oral mucosal lesions in elderly people in Santiago, Chile. JOralPathol Med 2003;32(10):571-5.

11. Oakley. Areca nut chewing habit among high school children in the commonwealth nation of Micronesia. Bulletin of the world health organisation 2005,83(9).

12. Zhang L, Cheung Jr KJ, Lam WL.Increased genetic damage in oral leukoplakia from high risk sites: potential impact on staging and clinical management. Cancer 2001;91(11):2148-55.

13. Sharma. prevalence of oral submucous fibrosis in patients visiting dental college in rural area of jaipur, Rajasthan. JIAOM R 2012;24(1):114

14. Axéll T, Rundquist L. Orallichenplanus--ademographicstudy. Community Dent Oral Epidemiol 1987;15(1):52-6.

15. Carrard V, Haas A, Rados P, Filho M, Oppermann R, Albandar J. Prevalence and risk indicators of oral mucosal lesions in an urban population from South Brazil. Oral Dis 2011;17(2):171-9.

16. Safadi RA. Prevalence of recurrent aphthous ulceration in Jordanian dental patients. Community DentOralEpidemiol 2002;30(4):277-85.

17. Chattopadhyay A, Chatterjee S. Risk indicators for recurrent aphthous ulcers among adults in the US. Community Dent Oral Epidemiol 2007;35(2):152-9

18. García-Pola Vallejo MJ, M artínez Díaz-Canel Al, García M artín JM . Risk factors for oral soft tissue lesions in an adult Spanish population. Community DentOralEpidemiol 2007;35(2):152-9. 